\title{
Overexpression of miR-21 promotes the proliferation and migration of cervical cancer cells via the inhibition of PTEN
}

\author{
JINGJIE XU ${ }^{1,2}$, WEI ZHANG ${ }^{1}$, QIONGYING LV ${ }^{1}$ and DINGJUN ZHU ${ }^{1}$ \\ ${ }^{1}$ The First Department of Gynaecology, Renmin Hospital of Wuhan University, Wuhan, Hubei 430060; \\ ${ }^{2}$ Department of Gynaecology, Inner Mongolia Corps Hospital of Chinese People's \\ Armed Police Forces, Hohhot, Inner Mongolia 010040, P.R. China
}

Received January 29, 2015; Accepted March 4, 2015

DOI: 10.3892/or.2015.3931

\begin{abstract}
The oncogenic miR-21 has been widely recognized to promote the development and progression of various types of malignant tumors, but not cervical cancers. The aim of this study was to examine the expression of miR-21 and PTEN in cervical cancer specimens using quantitative PCR. The miR-21 level was then manipulated in the cervical cancer lines and the regulation of miR-21 on the proliferation, migration and invasion of cervical cancer cells was determined. Additionally, we determined the role of PTEN in the miR-21-regulated proliferation, migration and invasion of cervical cancer cells. miR-21 was upregulated in the cervical cancer specimens, negatively correlating with the PTEN mRNA level. Transfection of the miR-21 mimics was markedly promoted, whereas the miR-21 inhibitor suppressed the proliferation, migration and invasion of cervical cancer cells, with a significant inhibition of PTEN expression. In addition, the overexpression of PTEN markedly inhibited the proliferation and migration of the cervical cancer cells. The present study showed the upregulation of miR-21 in invasive cervical cancers, and confirmed the promotion of miR-21 with regard to the proliferation, migration and invasion in cervical cancer cells via inhibiting the PTEN expression. To the best of our knowledge, this is the first study to confirm that the miR-21/PTEN pathway promotes cervical cancer.
\end{abstract}

\section{Introduction}

Cervical cancer remains the second leading malignancy for women worldwide $(1,2)$, although the incidence of this type of cancer is on the decrease in developed countries due to early diagnosis. Nevertheless, cervical cancer remains a serious health issue for women in developing countries, such as China, where diagnostic programs are not well

Correspondence to: Dr Wei Zhang, The First Department of Gynaecology, Renmin Hospital of Wuhan University, 238 Jiefang Road, Wuchang, Wuhan, Hubei 430060, P.R. China

E-mail: zhangweirhwu@163.com

Key words: miR-21, proliferation, migration, cervical cancer cells, PTEN established. Moreover, local recurrence remains challenging for those patients with cervical cancers (particularly at the advanced stage) (3), even though such therapies as surgery, chemotherapy and/or radiotherapy have been utilized.

Persistent cervical infection with high-risk human papillomavirus (HPV), particularly with HPV type 16 or 18 , contributes to the development of cervical cancer (4-6). The early oncoproteins of HPVs E5, E6 and E7 are known to contribute to tumor progression, such as the proliferation, migration and invasion of cervical cancer cells (7). Accumulating evidence has identified molecular mechanisms involved in cervical cancer. Molecules such as vascular endothelial growth factor-C (VEGF-C) (8), Src homology-2 domain containing protein, tyrosine phosphatase-2 (SHP-2) (9), or CD147 isoform-4 (CD147-4) (10) are known to promote the proliferation, migration or invasion of cervical cancers by activating focal adhesion kinases (8), through inhibition of interferon- $\beta$ production (9), or with an upregulated expression of the cancerous inhibitors PP2A (CIP2A), polo-like kinase (PLK) and cyclin D1 but a downregulated p27 expression (10). By contrast, tumor-suppressive molecules, such as Beclin1 (11) and histone deacetylase (HDAC) 10 (12) have been confirmed to inhibit the invasion and migration of cervical cancer cells by decreasing the expression of VEGF and matrix metalloproteinase (MMP)-9 proteins (11), or through the inhibition of MMP-2 and -9 expression (12).

A type of non-coding RNA with $\sim 22$ nucleotides, known as microRNAs (miRNAs) (13), has been found to be important in the development and progression of cervical cancers (14-16). Dysregulated miRNAs, such as miR-135a (17), miR-10a (18), or miR-205 (19) promote cell growth, migration and invasion in human cervical cancer cells, by regulating $\beta$-catenin (17), by targeting CHL1 (18), or by downregulating CYR61 and CTGF (19). Some tumor-suppressive microRNAs, such as miR-218 (20), miR-372 (21), or miR-214 (22) are also deregulated in cervical cancers and contribute to cancer progression. In addition, the oncogenic miR-21 has been widely recognized to play a role in non-small cell lung cancers (NSCLCs) $(23,24)$, as well as colorectal (25), ovarian (26), breast (27) and esophageal cancers (28). Accumulating evidence shows that the promoting role of miR-21 in NSCLCs or in colorectal cancers occurs through the modulation of the phosphatase and the tensin homolog (PTEN) signaling pathway $(24,25)$. Moreover, 
miR-21 has been demonstrated to be deregulated in cervical cancers, with a marked association with the worsening clinical diagnosis of cervical cancers (29).

In the present study, we examined the expression of miR-21 and PTEN in cervical cancer specimens, and investigated the regulation of miR-21 and PTEN on the proliferation and migration of the cervical cancer CaSki and HeLa cells. We also determined the regulation of miR-21 on the PTEN expression. The present study demonstrated the regulation of miR-21 on the progression of the cervical cancer cells.

\section{Materials and methods}

Human tissue specimens. The 36 invasive cervical cancer and 21 normal human cervical tissue specimens were collected using surgical resection prior to radiotherapy or chemotherapy. The tissue specimens were stored at $-80^{\circ} \mathrm{C}$ prior to utilization. Utilization of the cervical cancer specimens and normal cervical tissues was approved by the Hospital Internal Review Board (IRB) in our hospital.

Cell culture and recombinant plasmid transfection. The CaSki and HeLa cervical cancer cell lines were purchased from the American Type Culture Collection (Manassas, VA, USA) and grown, respectively, in RPMI-1640 medium (Sigma-Aldrich, St. Louis, MO, USA) or Eagle's minimum Essential medium (EMEM; Invitrogen, Carlsbad, CA, USA) supplemented with 10\% fetal bovine serum (FBS; Gibco, Rockville, MD, USA). The two cell types were incubated at $37^{\circ} \mathrm{C}$, with $5 \% \mathrm{CO}_{2}$. miR-21 mimics, miR-21 inhibitor or miRNA control (Qiagen, Valencia, CA, USA) were utilized to manipulate the miR-21 level. Then, 25 or $50 \mathrm{nM}$ miR-21 mimics, miR-21 inhibitor or miRNA control were transfected with Lipofectamine 2000 (Invitrogen) into the CaSki or HeLa cells.

To overexpress PTEN in the CaSki cells, we constructed a recombinant plasmid, PTEN-pcDNA3.1 (+) by cloning the PTEN (GenBank accession no. NG_007466.1) coding sequence into a eukaryotic expression vector, pcDNA3.1 (+) (Invitrogen). To overexpress the PTEN in the CaSki cells, the cells were transfected with the PTEN-pcDNA3.1 (+) or CAT-pcDNA3.1 (+) plasmid. The post-transfected cells were then cultured for $24 \mathrm{~h}$ to determine PTEN expression at the mRNA and protein levels. For the proliferation assay, the PTEN-overexpressed cells [CaSki PTEN (+)] or the CAT-overexpressed cells (CaSki control) were cultured for 24,48 or $72 \mathrm{~h}$. For the colony-forming assay, the CaSki PTEN (+) cells or the CaSki control cells were cultured for $48 \mathrm{~h}$.

RNA extraction and reverse transcripatse-quantitative $P C R$ $(R T-q P C R)$. Cellular mRNA was extracted from cervical cancer specimens or from cell samples using TRIzol reagent (Thermo Fisher Scientific, Waltham, MA, USA). cDNA from each sample was synthesized with the Superscript First-Strand Synthesis System for the RT-PCR kit (Gibco-BRL, Grand Island, NY, USA) with a random Uni-12 primer. The PTEN mRNA was quantified by RT-qPCR performed using a TaqMan Assay based on real-time detection in a LightCycler 2.0 (Roche Diagnostics GmbH, Mannheim, Germany). The PTEN mRNA level in each sample was normalized to $\beta$-actin.
A
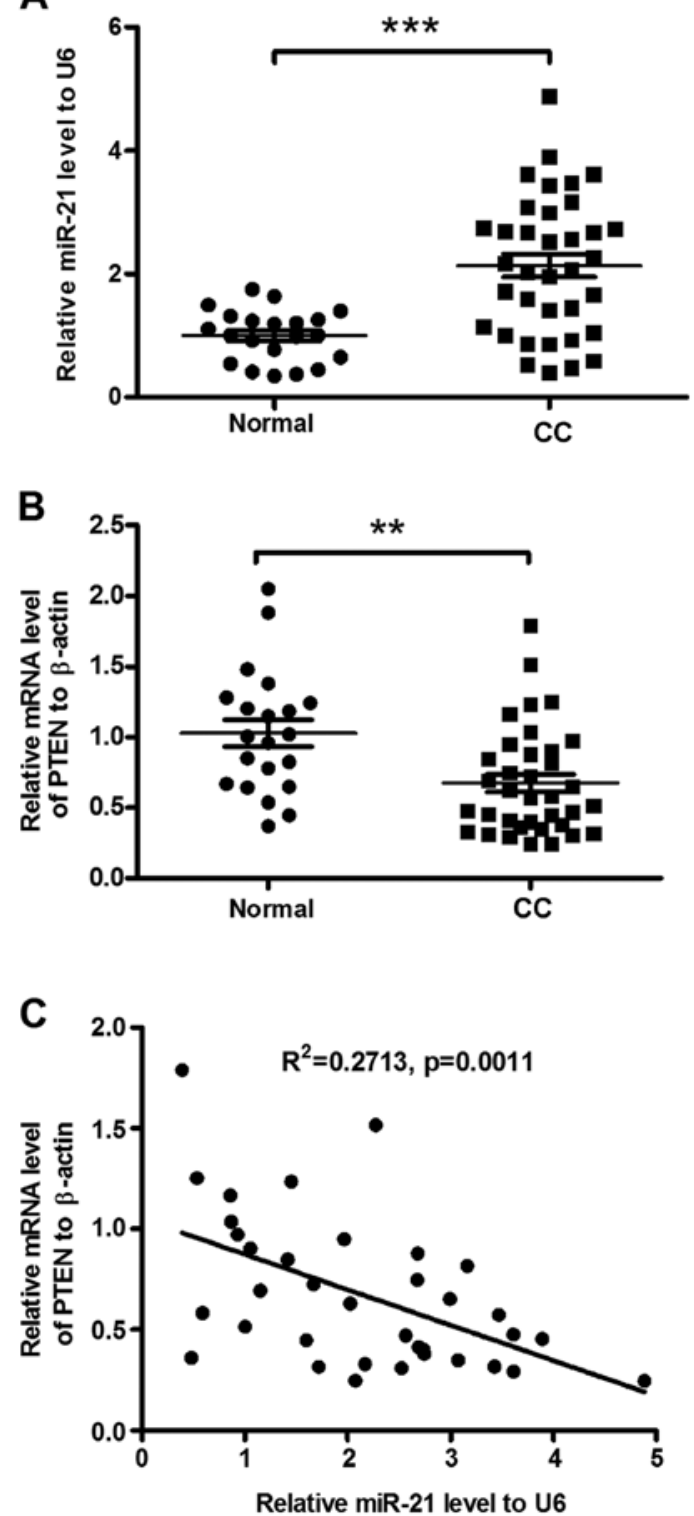

Figure 1. miR-21 level is upregulated in the cervical cancer (CC) specimens and negatively correlated with the PTEN mRNA level. The expression of (A) miR-21 and (B) relative PTEN mRNA was examined in the normal cervical tissues $(n=21)$ and CC samples $(n=36)$. (C) Negative correlation of upregulated miR-21 with downregulated PTEN mRNA level in the CC specimens. ${ }^{* *} \mathrm{P}<0.01$ and ${ }^{* * *} \mathrm{P}<0.001$, statistically significant.

miRNA extraction was performed using the mirVana miRNA Isolation kit (Ambion, Austin, TX, USA). Quantification of the miR-21 level in the cervical cancer specimens and cell samples was conducted using the mirVana RT-qPCR miRNA Detection kit (Ambion), with the U6 small nuclear RNA used as the internal control. The $\Delta \Delta \mathrm{Ct}$ method was used for relative quantification (30), and the PTEN mRNA or the miR-21 level was expressed as a relative value to the control group.

CCK-8 assay, cell colony-forming assay and proliferation. The Cell proliferation was examined using the CCK-8 assay. Briefly, CaSki or HeLa cells post-transfected with miR-21 mimics, miR-21 inhibitor or miR-21 control were incubated in CCK-8 (Dojindo, Kumamoto, Japan). Absorbance at $450 \mathrm{~nm}$ 
A
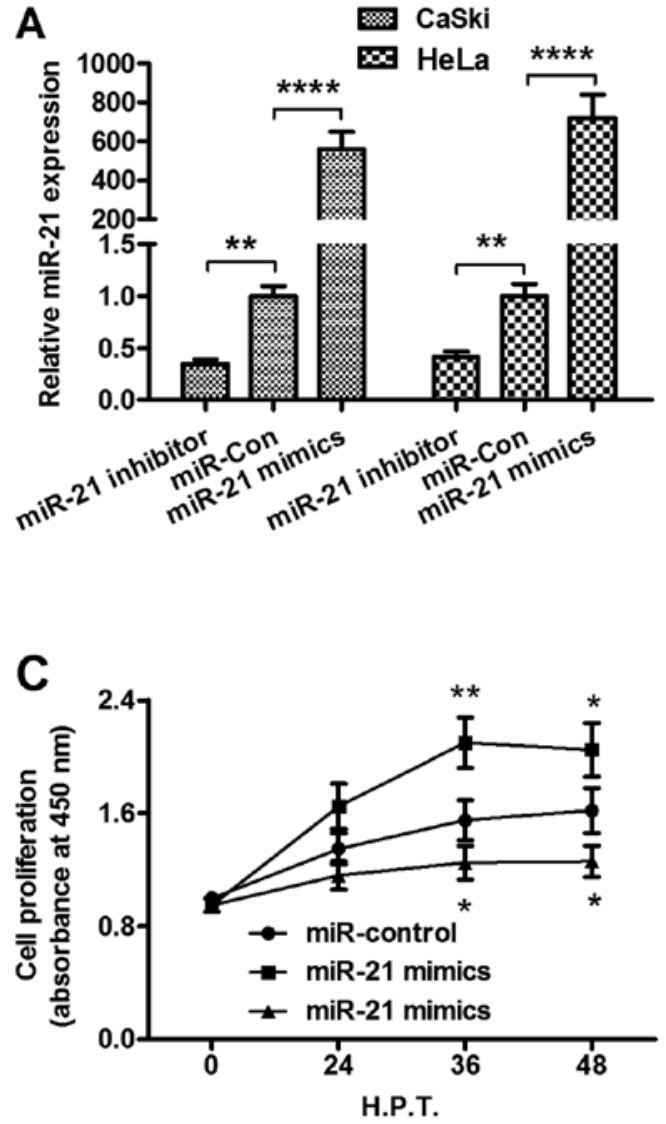
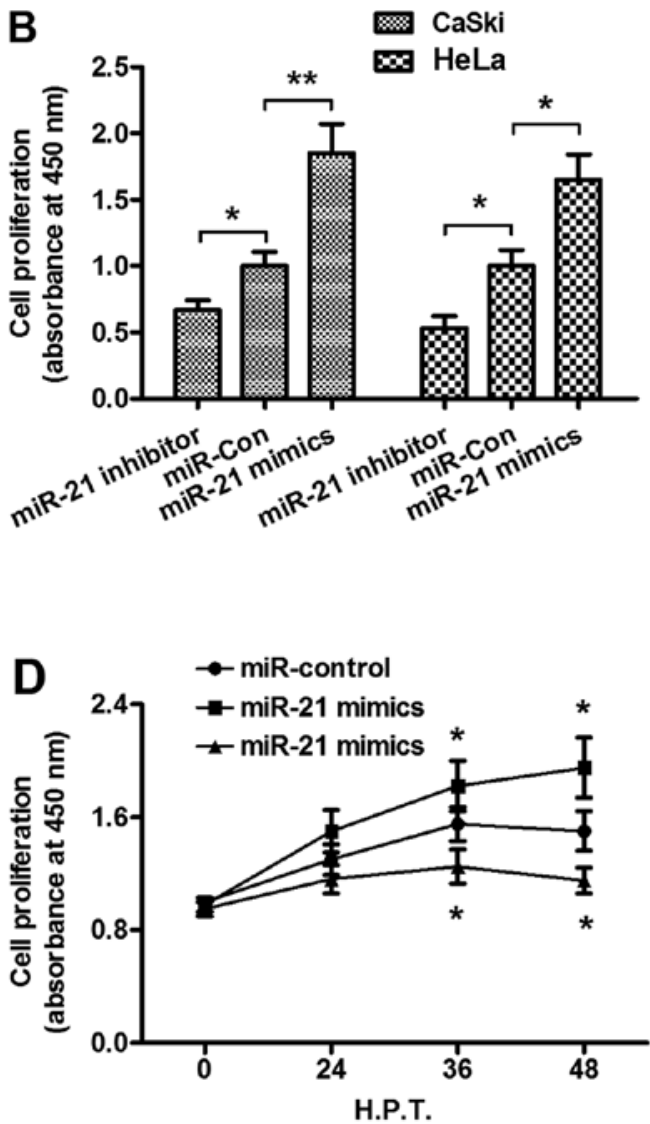

Figure 2. miR-21 manipulations with miR-21 mimics or miR-21 inhibitor promote or inhibit the proliferation of CaSki or HeLa cells in vitro. (A) The up- or downregulation of miR-21 by transfection with miR-21 mimics or with miR-21 inhibitor in the CaSki and HeLa cells. The miR-21 level was examined using RT-qPCR, $24 \mathrm{~h}$ following transfection with $25 \mathrm{nM}$ miR-control, miR-21 mimics or miR-21 inhibitor. (B) CCK-8 assay for the relative proliferation of the CaSki or HeLa cells, $24 \mathrm{~h}$ following transfection with $25 \mathrm{nM}$ miR-control, miR-21 mimics or miR-21 inhibitor. Growth curve of the (C) CaSki or (D) HeLa cells, following transfection with $25 \mathrm{nM}$ miR-control, miR-21 mimics or miR-21 inhibitor, examined by the CCK-8 assay. Each value was averaged for three independent results. ${ }^{*} \mathrm{P}<0.05,{ }^{* *} \mathrm{P}<0.01$ and ${ }^{* * * * *} \mathrm{P}<0.0001$, statistically significant differences. CCK- 8 , Cell Counting Kit- 8 .

of the treated cells was detected following incubation at $37^{\circ} \mathrm{C}$, with $5 \% \mathrm{CO}_{2}$, for 24,36 or $48 \mathrm{~h}$. For the cell colony-forming assay, $300 \mathrm{CaSki}$ or HeLa cells were incubated in 12-well plates at $37^{\circ} \mathrm{C}, 5 \% \mathrm{CO}_{2}$, and were then transfected with or without $50 \mathrm{nM}$ miR-21 mimics, miR-21 inhibitor or miRNA control. Following 48-h post-incubation, the cells were stained with crystal violet $(0.005 \%)$ for $20 \mathrm{~min}$ and the colony numbers were recorded using Image $\mathbf{J}$ software.

Cell migration and invasion assay. The ability of cell migration was examined by the wound-healing assay. The cells were seeded in 12-well plates and cultivated to a confluence of $85 \%$. The $85 \%$ confluent HeLa cells were then transfected with miR-21 mimics, miR-21 inhibitor or miR-21 control and were scratched with Cell Scrapers (Corning Inc., Corning, NY, USA), $6 \mathrm{~h}$ post-transfection. Cell growth was observed at 0,24 and $48 \mathrm{~h}$. The HeLa cells that migrated across the baseline were counted under an optical microscope. Cell invasion was examined by the Matrigel-coated Transwell assay. Briefly, the cells were seeded at a density of $1 \times 10^{5}$ cells in serum-free medium on the upper chamber with the a non-coated membrane $(8 \mu \mathrm{m}$ pore size; Millipore, Zug, Switzerland). The lower chamber contained medium with $20 \%$ FBS as a chemoattractant. The cells in the upper chamber were discarded using cotton wool after $24 \mathrm{~h}$ and the migratory cells in the lower chamber were counted under an optical microscope. The experiments were repeated in triplicate.

Statistical analysis. Data are presented as the mean \pm SEM. Statistical analysis was performed using the SPSS 18.0 software (IBM SPSS, Armonk, NY, USA). Correlations between the miR-21 and PTEN mRNA level in cervical cancer specimens were analyzed using the Spearman's rank correlation. PTEN expression at the mRNA or the protein levels, miR-21 expression, the colony-forming and the migratory cells between the two groups were analyzed using the Student's t-test. The cell proliferation difference among miR-21 mimics, miR-21 inhibitor and miRNA control groups was analyzed by the two-way ANOVA test. $\mathrm{P} \leq 0.05$ was considered to indicate a statistically significant difference.

\section{Results}

miR-21 is overexpressed in invasive cervical cancer specimens, in association with a reduced PTEN expression. The miR-21 level in the cervical cancer specimens was examined using RT-qPCR, compared to the normal cervical tissues. Thirty-six invasive cervical cancer patients with an average diagnosis age of 52 years were included in the study. Of the 36 subjects, 28 were HPV-positive and 8 were HPV-negative. The 

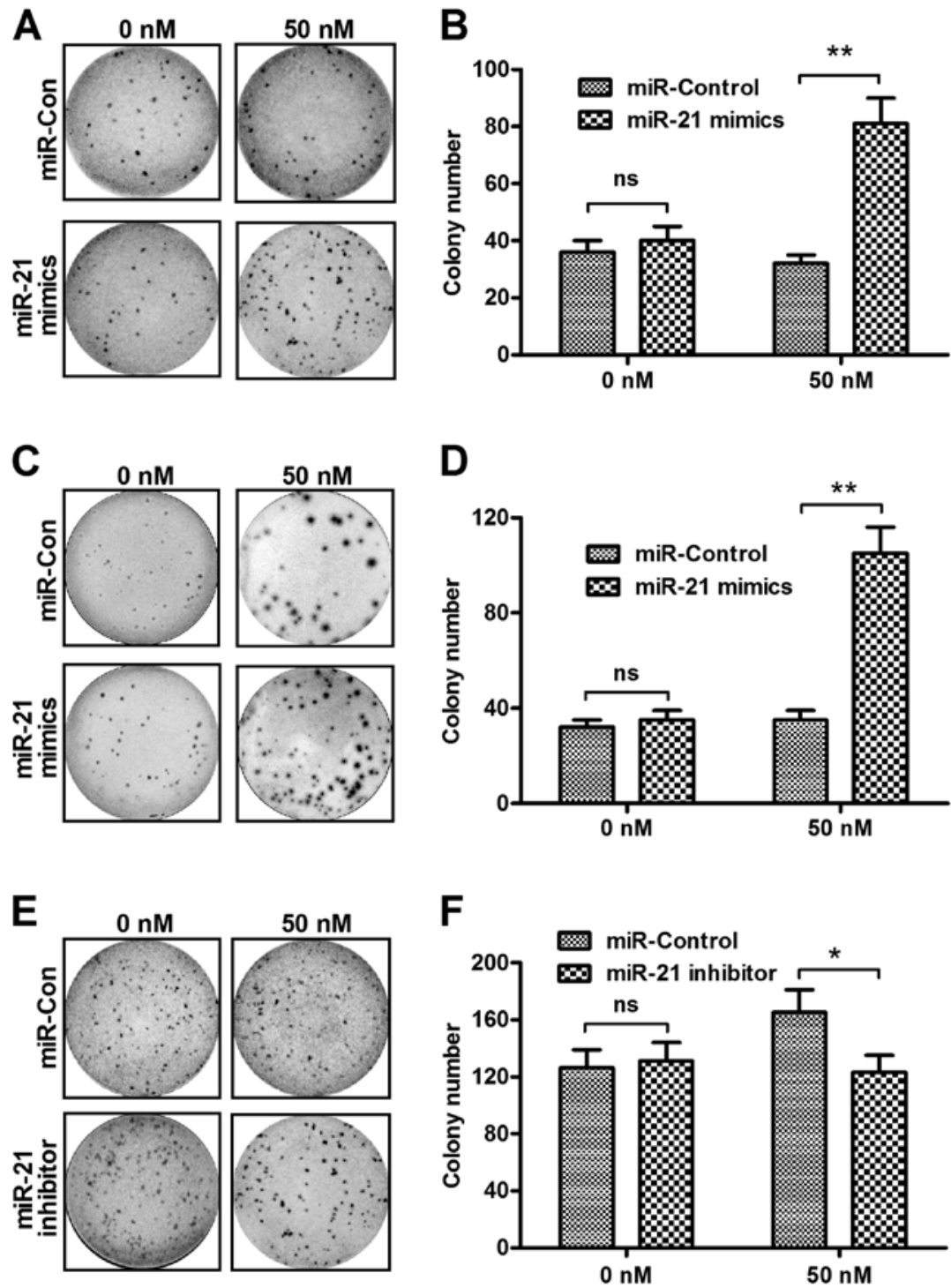

Figure 3. miR-21 manipulations with miR-21 mimics or miR-21 inhibitor regulate the colony formation of the CaSki or HeLa cells. (A) Colony forming of the CaSki cells following transfection with or without $50 \mathrm{nM}$ miR-21 mimics or miR-control. (B) Counting of colonies formed by the CaSki cells following transfection with miR-21 mimics or with miR-control. (C) Colony formation by the HeLa cells following transfection with or without $50 \mathrm{nM}$ miR-21 mimics or miR-control. (D) Counting of colonies formed by HeLa cells following transfection with miR-21 mimics or with miR-control. (E) Colony formation by the HeLa cells following transfection with or without $50 \mathrm{nM}$ miR-21 mimics or miR-control. (F) Counting of colonies formed by the CaSki cells following transfection with miR-21 mimics or with miR-control. The experiments were performed in triplicate. ${ }^{*} \mathrm{P}<0.05,{ }^{* *} \mathrm{P}<0.01$, statistical significance. ns, not significant.

mean value of miR-21 was $2.14 \pm 0.19$ in the 36 samples from patients with cervical cancer and $1.00 \pm 0.09$ in the healthy controls $(\mathrm{P}<0.001$, Fig. 1A). No significant difference was identified in the miR-21 level between the HPV-positive and -negative samples. Thus, miR-21 was confirmed to be significantly upregulated in the invasive cervical cancer specimens. It has been indicated that the tumor-suppressive phosphatase and tensin homolog (PTEN) (31) is downregulated in cervical cancers $(29,32,33)$. To investigate the association of the upregulated miR-21 level with the downregulated PTEN in cervical cancers, we examined the expression of PTEN mRNA. As shown in Fig. 1B, there was a significant reduction of PTEN mRNA in the invasive cervical cancer specimens $(\mathrm{P}<0.01)$. Downregulation of PTEN correlated with the miR-21 upregulation in the specimens $\left(\mathrm{R}^{2}=0.2713, \mathrm{P}=0.0011\right.$, Fig. $\left.1 \mathrm{C}\right)$. Thus, miR-21 overexpression was confirmed in the invasive cervical cancer specimens, in association with the PTEN downregulation.

Manipulation of the miR-21 level regulates the proliferation of cervical cancer cells. To identify the regulation of miR-21 on the proliferation of the cervical cancer cells, we manipulated the miR-21 level in the CaSki and HeLa cells by transfecting the cells with miR-21 mimics, miR-21 inhibitor or miRNA control. There was a significant increase or reduction in the miR-21 level in the CaSki or HeLa cells post-transfected with miR-21 mimics or miR-21 inhibitor $(\mathrm{P}<0.01$ or $\mathrm{P}<0.0001$ for the miR-21 inhibitor or miR-21 mimics in the CaSki or HeLa cells, Fig. 2A). Proliferation of the CaSki and HeLa cells following transfection with miR-21 mimics, miR-21 inhibitor or miRNA control was assessed using the CCK-8 assay. In the CaSki or HeLa cells, the miR-21 mimics promoted cell 
A
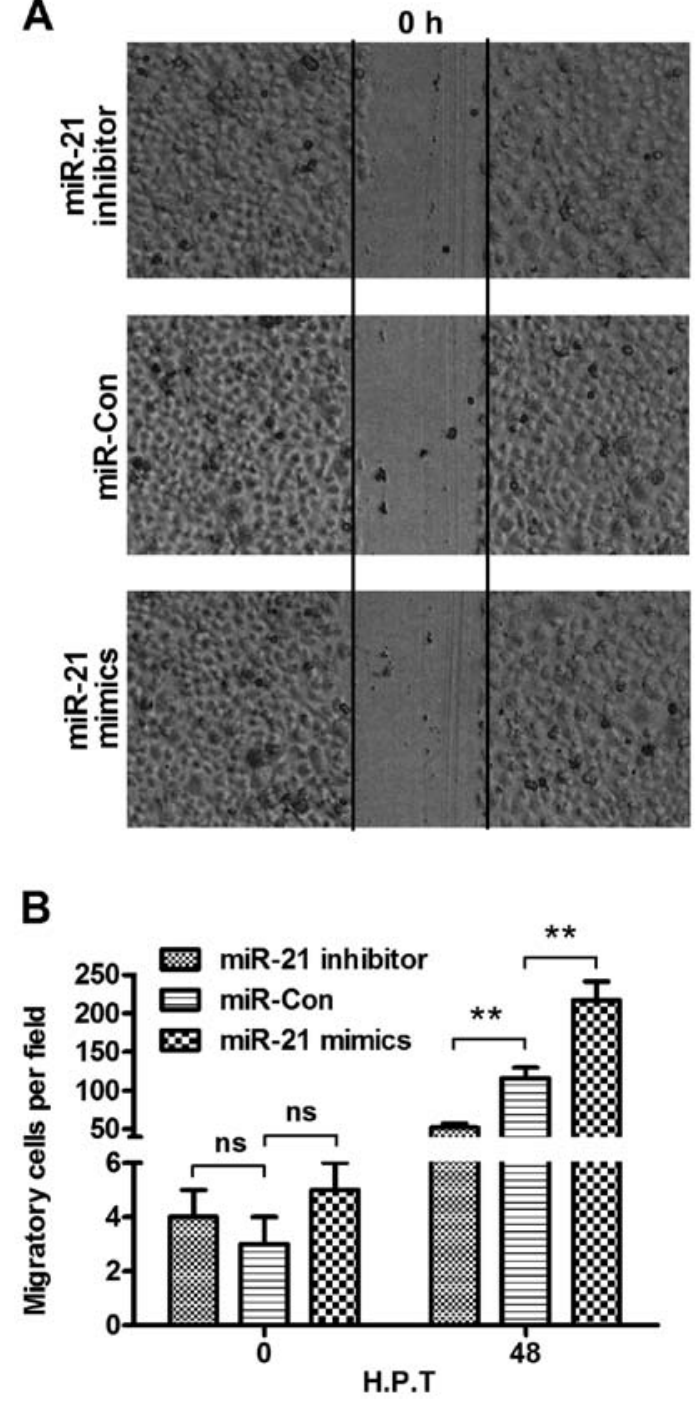

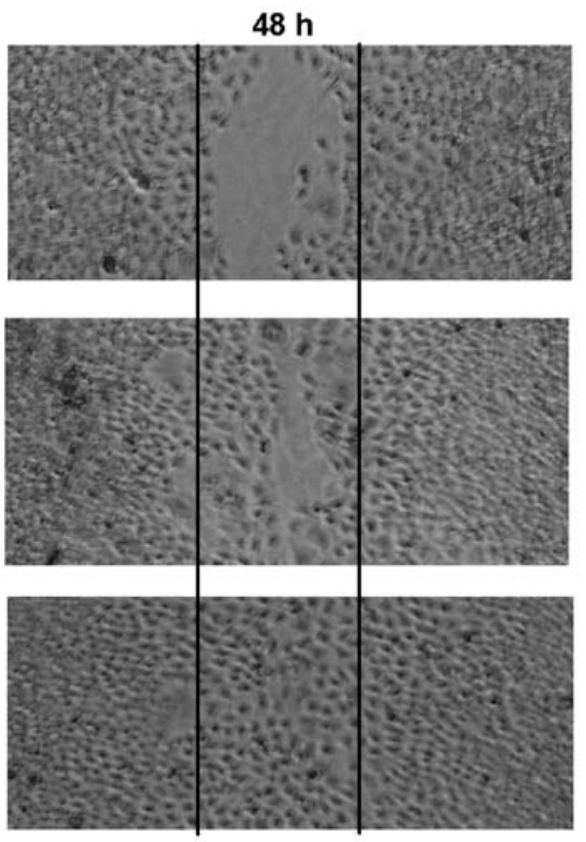

C

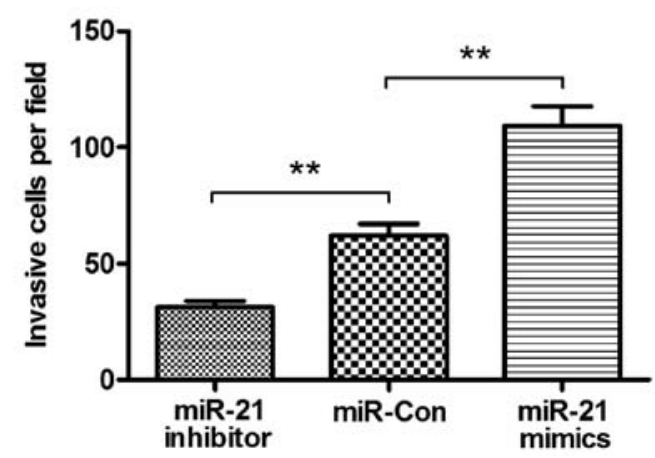

Figure 4. miR-21 manipulations with miR-21 mimics or miR-21 inhibitor regulates the migration of HeLa cells. (A) The wound-healing assay was performed on HeLa cells, 0 or $48 \mathrm{~h}$ following transfection with miR-21 inhibitor, miR control or miR-21 mimics. Cell migration was depicted following incubation at 0 , or $48 \mathrm{~h}$ following cell scratch. The solid lines show the edges at the initiation of the experiments. (B) Migratory cell counting of the HeLa cells following transfection with miR-21 inhibitor, miR control or miR-21 mimics. (C) Cell invasion was determined by the Matrigel-coated Transwell assay. The cells that crossed the Matrigel-coated filter were fixed, stained and counted. Data are presented as the mean \pm SEM for three independent experiments. Statistical significance was shown as ${ }^{* *} \mathrm{P}<0.01$. ns, not significant.

proliferation instead of miRNA control $(\mathrm{P}<0.01$ and $\mathrm{P}<0.05$ for the CaSki and HeLa cells, respectively, Fig. 2B), whereas the miR-21 inhibitor transfection inhibited the proliferation of the CaSki and HeLa cells (both $\mathrm{P}<0.05$, Fig. 2B). There was also a time dependence in the regulation on the proliferation of the CaSki (Fig. 2C) or HeLa cells (Fig. 2D).

To confirm the proliferation regulation by miR-21 manipulation, we performed a colony formation assay of the CaSki and HeLa cells transfected with miR-21 mimics, miR-21 inhibitor or miRNA control. Fig. 3A shows that, the CaSki cells formed more colonies following transfection with $50 \mathrm{nM}$ miR-21 mimics as compared to the control miRNA (Fig. 3B, $\mathrm{P}<0.01$ ). The promotion of colony formation by the miR-21 mimics transfection was reconfirmed in HeLa cells and the transfection with the miR-21 mimics promoted more colonies in HeLa cells than the transfection with control miRNA (Fig. 3C and D, $\mathrm{P}<0.01)$. On the other hand, the miR-21 inhibitor suppressed colony formation in the CaSki cells with a transfection concentration of $50 \mathrm{nM}$ (Fig. 3E and F, P<0.05). These findings demonstrated that upregulated miR-21 enhanced the proliferative ability and colony formation of cervical cancer cells.

Manipulation of miR-21 level regulates the migration and invasion of cervical cancer cells. To identify the oncogenic promotion of miR-21, the migration and invasion of the cervical cancer cells were evaluated using the wound-healing and Transwell assays. Firstly, the difference in the migration of HeLa cells post-transfected with $50 \mathrm{nM}$ miR-21 mimics, miR-21 inhibitor or control miRNA using a wound-healing assay was determined. Fig. 4A shows that there were more HeLa cells migrating across the baseline in the miR-21 mimics transfection group as compared to that in the control miRNA transfection group $(\mathrm{P}<0.01$, Fig. $4 \mathrm{~B})$, whereas the miR-21 inhibitor reduced HeLa cell migration as compared to that in the control group $(\mathrm{P}<0.01$, Fig. 4B). In addition, we investigated cell invasion using the Transwell assay. Fig. 4C shows 

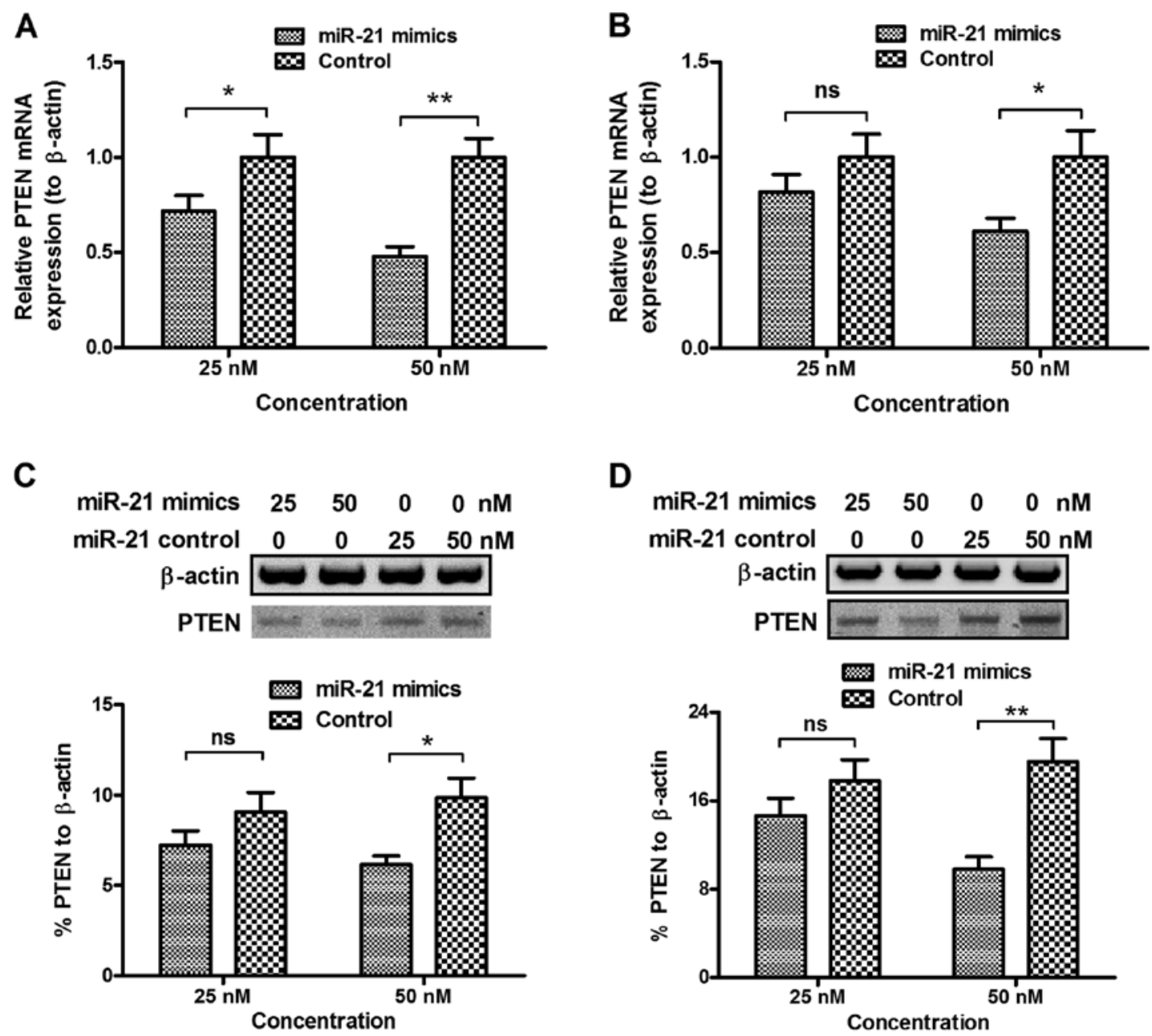

Figure 5. miR-21 mimics transfection inhibits PTEN expression at the mRNA and protein levels. PTEN mRNA level in the (A) CaSki or (B) HeLa cells $24 \mathrm{~h}$ following transfection with 25 or $50 \mathrm{nM}$ miR-21 mimics. (C and D) PTEN at the protein level in the (A) CaSki or (B) HeLa cells $48 \mathrm{~h}$ following transfection with 25 or $50 \mathrm{nM}$ miR-21 mimics or miR control. The experiments were performed in triplicate. ${ }^{*} \mathrm{P}<0.05$ and ${ }^{* *} \mathrm{P}<0.01$, statistically significant. ns, not significant.

that the invaded cells in the miR-21 mimics transfection group were significantly more than those in the control miRNA group $(\mathrm{P}<0.01)$, whereas the invaded cells in the miR-21 inhibitor transfection group were significantly less than those in the control miRNA group $(\mathrm{P}<0.01)$. Collectively, miR-21 promoted the migration and invasion of cervical cancer cells.

miR-21 mimics transfection significantly downregulates the PTEN level in cervical cancer cells. To identify the mechanism involved in the promotion of miR-21 to the proliferation of the CaSki or HeLa cells, and to investigate the regulation of PTEN expression by miR-21 in the cervical cancer cells, we examined PTEN expression at the mRNA and protein levels in the CaSki and HeLa cells following transfection with miR-21 mimics or miRNA control. PTEN was downregulated at the mRNA level in the CaSki cells by transfection with 25 or $50 \mathrm{nM}$ miR-21 mimics $(\mathrm{P}<0.05$ for $25 \mathrm{nM}$ or $\mathrm{P}<0.01$ for $50 \mathrm{nM}$, Fig. 5A). This downregulation in the PTEN mRNA was confirmed in the HeLa cells, where transfection with $50 \mathrm{nM}$ miR-21 mimics significantly downregulated PTEN mRNA in the HeLa cells $(\mathrm{P}<0.05$, Fig. 5A). By contrast, there was no regulation of the PTEN mRNA level by the control miRNA transfection (Fig. 5A and B). To reconfirm the PTEN downregulation by miR-21, we analyzed PTEN expression at the protein level which was examined in cells following transfection with miR-21 mimics or miRNA control. Fig. 5C shows that transfection with $50 \mathrm{nM}$ miR-21 mimics, instead of the $50 \mathrm{nM}$ control miRNA reduced PTEN expression at the protein level $(\mathrm{P}<0.05)$. Furthermore, the PTEN reduction by transfection with $50 \mathrm{nM}$ miR-21 mimics was observed in the HeLa cells $(\mathrm{P}<0.01$, Fig. 5D). Therefore, miR-21 mimics transfection significantly downregulated the PTEN level in the cervical cancer cells.

PTEN overexpression inhibits cervical cancer cell proliferation. To determine whether miR-21-promoted cervical cancer proliferation was mediated by the downregulation of PTEN, we overexpressed PTEN with a eukaryotic expression vector, pcDNA3.1(+), in the CaSki cells. Then, we examined the proliferation of CaSki cells with PTEN overexpressed [CaSki PTEN(+)] or CaSki cells transfected with CAT-pcDNA3.1(+) (CaSki control) using the CCK-8 assay. Figs. 6A and $\mathrm{B}$ shows that there was a significantly overexpressed PTEN at the mRNA (Fig. 6A) and protein (Fig. 6B) levels in the CaSki PTEN(+) cells, compared to the CaSki control cells. Furthermore, the CCK- 8 assay indicated that, 
A

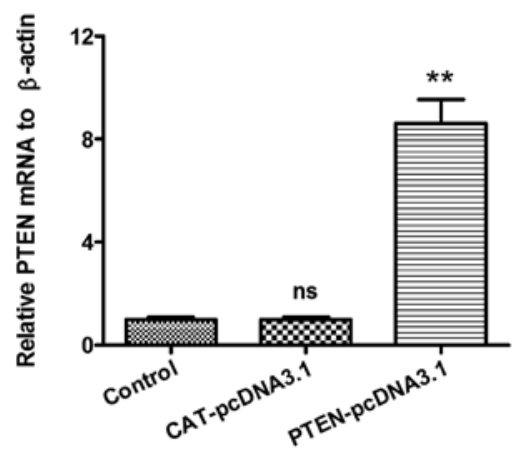

C

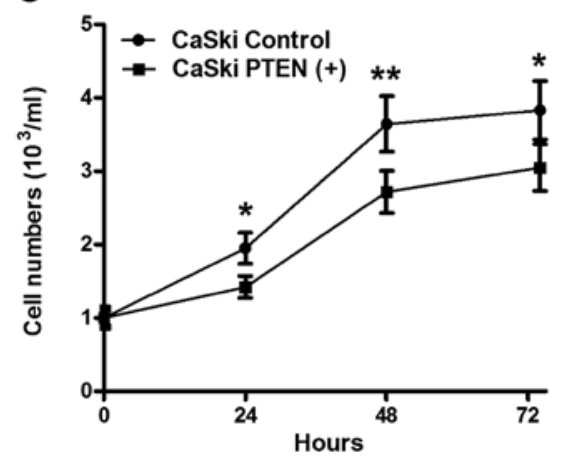

E

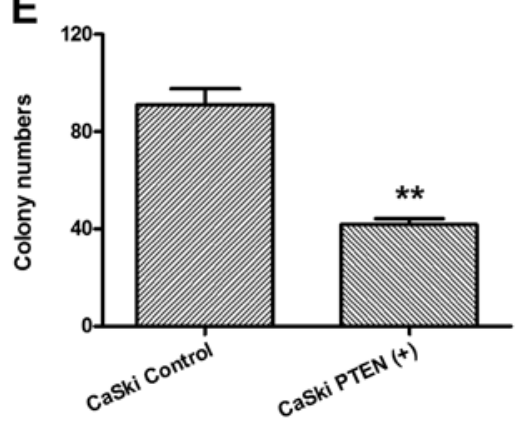

B
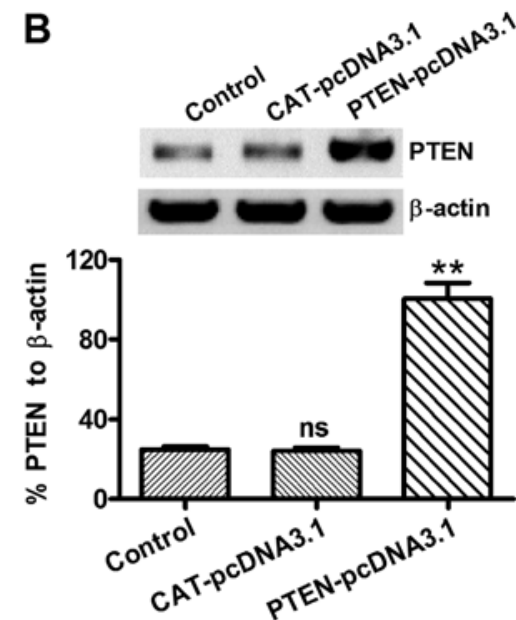

D
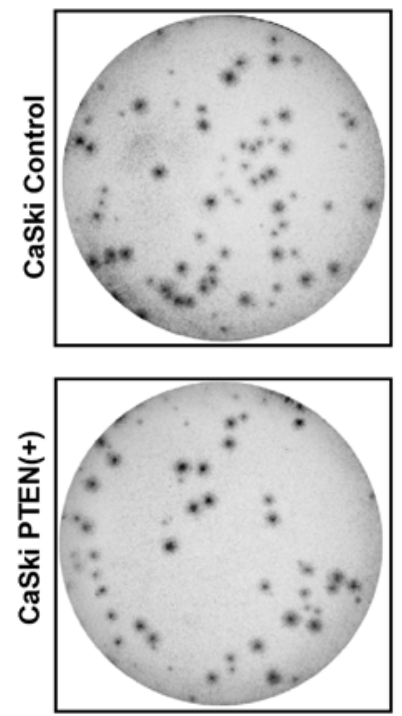

Figure 6. PTEN overexpression promotes the proliferation and colony formation of HeLa cells. PTEN at the (A) mRNA or (B) protein level in the mock HeLa cells. HeLa cells were transfected with CAT-pcDNA3.1 or PTEN-pcDNA3.1 plasmids. (C) Proliferation difference between the PTEN-overexpressed and control HeLa cells. (D) Colony formation by the PTEN-overexpressed or control HeLa cells. (E) Counting of colonies formed by the PTEN-overexpressed or control HeLa cells. The results are the average of three independent experiments. ${ }^{*} \mathrm{P}<0.05$, statistically significant difference. ${ }^{* *} \mathrm{P}<0.01$; ns, not significant.

from 24 to $72 \mathrm{~h}$ following incubation, the CaSki PTEN(+) cells grew to a significantly lower level than the CaSki control cells (Fig. 6C, $\mathrm{P}<0.05$ for 24 or $72 \mathrm{~h}$ and $\mathrm{P}<0.01$ for $48 \mathrm{~h}$ ). As shown in Fig. 6D and E, the colony-forming assay confirmed the lower proliferation of CaSki PTEN(+) cells, compared to the CaSki control cells $(\mathrm{P}<0.01)$. These results indicated that the overexpression of PTEN inhibited the proliferation of cervical cancer cells.

\section{Discussion}

Increased miR-21 has been identified in various types of cancer (34-38), such as colorectal (25), hepatocellular (35) and breast cancers $(27,36,37)$. It has been reported that miR-21 expression increased with worsening clinical diagnosis in cervical cancers (29). The cytoplasmic expression of the programmed cell death 4 (PDCD4) protein, which is a known target of miR-21 (39), was also significantly lower in women with invasive cervical carcinoma (ICC) (29). However, there was no significant correlation between miR-21 overexpression and PDCD4 downregulation. Thus, there may be other target molecules for miR-21 in invasive cervical cancers. The PTEN gene is mutated or abrogated in a wide range of human cancers (40-42). The tumor suppressive PTEN inhibits cell migration and invasion by directly dephosphorylating two key tyrosine-phosphorylated proteins, thereby antagonizing the interactions of integrins with the extracellular matrix and integrin-triggered signaling pathways $(43,44)$. The 
dephosphorylating role of PTEN is also necessary in a lipid signal transduction pathway (45). Therefore, PTEN performs as a unique tumor suppressor through the inhibition of lipid phosphatase and protein tyrosine phosphatase activities, thus negatively regulating cell proliferation and invasion. The tumor suppressive PTEN gene has also been reported to mutate or to decrease in expression in cervical cancers $(32,46)$. However, its role in the proliferation or invasion of cervical cancers needs to be determined in detail.

In the present study, we found that miR-21 was overexpressed, whereas PTEN was downregulated in the invasive cervical cancer specimens, and that miR-21 overexpression was associated with the downregulated PTEN in such cervical cancer specimens. To recognize the oncogenic role of miR-21 in the cervical cancer cells, we manipulated miR-21, with miR-21 mimics or miR-21 inhibitor in the CaSki and HeLa cervical cancer cell lines, and examined the regulation of miR-21 on cell proliferation and migration. Results in the present study confirm that the proliferation of CaSki or HeLa cells was promoted by transfection with miR-21 mimics, whereas proliferation was inhibited by transfection with the miR-21 inhibitor, in a time-dependent manner. Furthermore, the migration and invasion of the cervical cancer cells was evaluated by the wound-healing and Transwell assays, following miR-21 manipulation. The results show that there were more HeLa cells migrating across the baseline in the miR-21 mimics transfection group, in comparison to the control miRNA transfection, whereas the miR-21 inhibitor reduced HeLa cell migration, compared to that in the control group. In addition, the Transwell assay indicated that the invaded cells were more in the miR-21 mimics transfection group than in the control miRNA group. Collectively, miR-21 promoted the proliferation, migration and invasion of the cervical cancer cells.

Given the regulation by miR-21 on PTEN expression in various types of cancer $(24,25,47)$, PTEN expression at the mRNA and protein levels was also examined in the CaSki or HeLa cells following transfection with miR-21 mimics or miRNA control. The results show that PTEN was downregulated at the mRNA and protein levels in the CaSki or HeLa cells by miR-21 mimics transfection, in comparison to the control miRNA transfection. Therefore, miR-21 mimics transfection significantly downregulated the PTEN level in the cervical cancer cells. Moreover, to identify the association of miR-21-promoted cervical cancer, proliferation and invasion were mediated by the downregulation of PTEN. We then overexpressed PTEN in the CaSki cells and investigated the regulation of CaSki cell proliferation by PTEN overexpression. The results show that the manipulated upregulation of the PTEN expression at the mRNA and protein levels in the CaSki cells significantly reduced cell proliferation.

In summary, the present study has shown the upregulation of miR-21 in invasive cervical cancers and confirms the promotion of miR-21 to the proliferation, migration and invasion in the CaSki or HeLa cervical cancer cells by downregulating the tumor-suppressive PTEN expression. To the best of our knowledge, this is the first study to confirm that the miR-21/PTEN pathway promotes cervical cancers, suggesting that the miR-21/PTEN pathway may be an effective target for cervical cancer treatment.

\section{References}

1. Jemal A, Siegel R, Xu J and Ward E: Cancer statistics, 2010. CA Cancer J Clin 60: 277-300, 2010.

2. Movva S, Rodriguez L, Arias-Pulido H and Verschraegen C: Novel chemotherapy approaches for cervical cancer. Cancer 115 : 3166-3180, 2009.

3. Sittidilokratna K, Cheewakriangkrai C, Khunamornpong S and Siriaunkgul S: Recurrence patterns after radical hysterectomy in stage IB1-IIA cervical. Asian Pac J Cancer Prev 11: 499-502, 2010.

4. zur Hausen H: Papillomavirus infections-a major cause of human cancers. Biochim Biophys Acta 1288: F55-F78, 1996.

5. de Sanjose S, Quint WG,Alemany L, Geraets DT, Klaustermeier JE, Lloveras B, Tous S, Felix A, Bravo LE, Shin HR, et al: Retrospective international survey and HPV time trends study group: Human papillomavirus genotype attribution in invasive cervical cancer: a retrospective cross-sectional worldwide study. Lancet Oncol 11: 1048-1056, 2010

6. Schiffman M, Castle PE, Jeronimo J, Rodriguez AC and Wacholder S: Human papillomavirus and cervical cancer. Lancet 370: 890-907, 2007.

7. Liao S, Deng D, Zhang W, Hu X, Wang W, Wang H, Lu Y, Wang S, Meng L and Ma D: Human papillomavirus 16/18 E5 promotes cervical cancer cell proliferation, migration and invasion in vitro and accelerates tumor growth in vivo. Oncol Rep 29: 95-102, 2013

8. Chen H, Suo K, Cheng Y,Zheng B and Xu L: Vascular endothelial growth factor $\mathrm{C}$ enhances cervical cancer migration and invasion via activation of focal adhesion kinase. Gynecol Endocrinol 29: 20-24, 2013.

9. Meng F, Zhao X and Zhang S: SHP-2 phosphatase promotes cervical cancer cell proliferation through inhibiting interferon- $\beta$ production. J Obstet Gynaecol Res 39: 272-279, 2013.

10. Wu Y, Zhou X and Zheng PS: Involvement of CD147 isoform 4 in the proliferation of SiHa cells: A possible molecular mechanism of cervical cancer. Oncol Rep 26: 717-724, 2011.

11. Sun Y, Liu JH, Sui YX, Jin L, Yang Y, Lin SM and Shi H: Beclin1 overexpression inhibitis proliferation, invasion and migration of CaSki cervical cancer cells. Asian Pac J Cancer Prev 12: 1269-1273, 2011

12. Song C, Zhu S, Wu C and Kang J: Histone deacetylase (HDAC) 10 suppresses cervical cancer metastasis through inhibition of matrix metalloproteinase (MMP) 2 and 9 expression. J Biol Chem 288: 28021-28033, 2013.

13. Siomi H and Siomi MC: Posttranscriptional regulation of microRNA biogenesis in animals. Mol Cell 38: 323-332, 2010.

14. Lee JW, Choi CH, Choi JJ, Park YA, Kim SJ, Hwang SY, Kim WY, Kim TJ, Lee JH, Kim BG, et al: Altered MicroRNA expression in cervical carcinomas. Clin Cancer Res 14: 2535-2542, 2008.

15. Lui WO, Pourmand N, Patterson BK and Fire A: Patterns of known and novel small RNAs in human cervical cancer. Cancer Res 67: 6031-6043, 2007.

16. Pereira PM, Marques JP, Soares AR, Carreto L and Santos MA: MicroRNA expression variability in human cervical tissues. PLoS One 5: el1780, 2010.

17. Leung CO, Deng W, Ye TM, Ngan HY, Tsao SW, Cheung AN, Pang RT and Yeung WS: miR-135a leads to cervical cancer cell transformation through regulation of $\beta$-catenin via a SIAH1dependent ubiquitin proteosomal pathway. Carcinogenesis 35: 1931-1940, 2014.

18. Long MJ, Wu FX, Li P, Liu M, Li X and Tang H: MicroRNA-10a targets CHL1 and promotes cell growth, migration and invasion in human cervical cancer cells. Cancer Lett 324: 186-196, 2012.

19. Xie H, Zhao Y, Caramuta S, Larsson C and Lui WO: miR-205 expression promotes cell proliferation and migration of human cervical cancer cells. PLoS One 7: e46990, 2012.

20. Yu J, Wang Y, Dong R, Huang X, Ding S and Qiu H: Circulating microRNA-218 was reduced in cervical cancer and correlated with tumor invasion. J Cancer Res Clin Oncol 138: 671-674, 2012.

21. Tian RQ, Wang XH, Hou LJ, Jia WH, Yang Q, Li YX, Liu M, Li X and Tang H: MicroRNA-372 is down-regulated and targets cyclin-dependent kinase 2 (CDK2) and cyclin A1 in human cervical cancer, which may contribute to tumorigenesis. J Biol Chem 286: 25556-25563, 2011.

22. Peng RQ,Wan HY,Li HF,Liu M,Li X and Tang H: MicroRNA-214 suppresses growth and invasiveness of cervical cancer cells by targeting UDP-N-acetyl- $\alpha$-D-galactosamine: polypeptide $\mathrm{N}$-ace tylgalactosaminyltransferase 7. J Biol Chem 287: 14301-14309, 2012. 
23. Wang Y, Li J, Tong L, Zhang J, Zhai A, Xu K, Wei L and Chu M: The prognostic value of miR-21 and miR-155 in non-small-cell lung cancer: A meta-analysis. Jpn J Clin Oncol 43: 813-820, 2013.

24. Liu ZL, Wang H, Liu J and Wang ZX: MicroRNA-21 (miR-21) expression promotes growth, metastasis, and chemo- or radioresistance in non-small cell lung cancer cells by targeting PTEN. Mol Cell Biochem 372: 35-45, 2013.

25. Xiong $\mathrm{B}$, Cheng $\mathrm{Y}, \mathrm{Ma} \mathrm{L}$ and Zhang $\mathrm{C}$ : miR-21 regulates biological behavior through the PTEN/PI-3 K/Akt signaling pathway in human colorectal cancer cells. Int J Oncol 42 219-228, 2013.

26. Liu S, Fang Y, Shen H, Xu W and Li H: Berberine sensitizes ovarian cancer cells to cisplatin through miR-21/PDCD4 axis. Acta Biochim Biophys Sin (Shanghai) 45: 756-762, 2013.

27. Teng Y, Manavalan TT, Hu C, Medjakovic S, Jungbauer A and Klinge CM: Endocrine disruptors fludioxonil and fenhexamid stimulate miR-21 expression in breast cancer cells. Toxicol Sci 131: 71-83, 2013

28. Alder H, Taccioli C, Chen H, Jiang Y, Smalley KJ, Fadda P, Ozer HG, Huebner K, Farber JL, Croce CM, et al: Dysregulation of miR-31 and miR-21 induced by zinc deficiency promotes esophageal cancer. Carcinogenesis 33: 1736-1744, 2012.

29. Deftereos G, Corrie SR, Feng Q, Morihara J, Stern J, Hawes SE and Kiviat NB: Expression of mir-21 and mir-143 in cervical specimens ranging from histologically normal through to invasive cervical cancer. PLoS One 6: e28423, 2011.

30. Livak KJ and Schmittgen TD: Analysis of relative gene expression data using real-time quantitative PCR and the 2(-Delta Delta C(T)) method. Methods 25: 402-408, 2001.

31. Chu EC and Tarnawski AS: PTEN regulatory functions in tumor suppression and cell biology. Med Sci Monit 10: RA235-RA241, 2004

32. Vázquez-Ulloa E, Lizano M, Avilés-Salas A, Alfaro-Moreno E and Contreras-Paredes A: Abnormal distribution of hDlg and PTEN in premalignant lesions and invasive cervical cancer. Gynecol Oncol 122: 663-668, 2011.

33. Hsieh SM, Maguire DJ, Lintell NA, McCabe M and Griffiths LR PTEN and NDUFB8 aberrations in cervical cancer tissue. Adv Exp Med Biol 599: 31-36, 2007.

34. Meng F, Henson R, Wehbe-Janek H, Ghoshal K, Jacob ST and Patel T: MicroRNA-21 regulates expression of the PTEN tumor suppressor gene in human hepatocellular cancer. Gastroenterology 133: 647-658, 2007.

35. Zhu S, Si ML, Wu H and Mo YY: MicroRNA-21 targets the tumor suppressor gene tropomyosin 1 (TPM1). J Biol Chem 282 14328-14336, 2007.
36. Iorio MV, Ferracin M, Liu CG, Veronese A, Spizzo R, Sabbioni S, Magri E, Pedriali M, Fabbri M, Campiglio M, et al: MicroRNA gene expression deregulation in human breast cancer. Cancer Res 65: 7065-7070, 2005.

37. Sempere LF, Christensen M, Silahtaroglu A, Bak M, Heath CV, Schwartz G, Wells W, Kauppinen S and Cole CN: Altered MicroRNA expression confined to specific epithelial cell subpopulations in breast cancer. Cancer Res 67: 11612-11620, 2007.

38. Si ML, Zhu S, Wu H, Lu Z, Wu F and Mo YY: miR-21-mediated tumor growth. Oncogene 26: 2799-2803, 2007.

39. Roldo C, Missiaglia E, Hagan JP, Falconi M, Capelli P, Bersani S, Calin GA, Volinia S, Liu CG, Scarpa A, et al: MicroRNA expression abnormalities in pancreatic endocrine and acinar tumors are associated with distinctive pathologic features and clinical behavior. J Clin Oncol 24: 4677-4684, 2006.

40. Li J, Yen C, Liaw D, Podsypanina K, Bose S, Wang SI, Puc J, Miliaresis C, Rodgers L, McCombie R, et al: PTEN, a putative protein tyrosine phosphatase gene mutated in human brain, breast, and prostate cancer. Science 275: 1943-1947, 1997.

41. Sakai A, Thieblemont C, Wellmann A, Jaffe ES and Raffeld M: PTEN gene alterations in lymphoid neoplasms. Blood 92: 3410-3415, 1998

42. Tashiro H, Blazes MS, Wu R, Cho KR, Bose S, Wang SI, Li J, Parsons R and Ellenson LH: Mutations in PTEN are frequent in endometrial carcinoma but rare in other common gynecological malignancies. Cancer Res 57: 3935-3940, 1997.

43. Li DM and Sun H: TEP1, encoded by a candidate tumor suppressor locus, is a novel protein tyrosine phosphatase regulated by transforming growth factor beta. Cancer Res 57: 2124-2129, 1997.

44. Li L, Ernsting BR, Wishart MJ, Lohse DL and Dixon JE: A family of putative tumor suppressors is structurally and functionally conserved in humans and yeast. J Biol Chem 272: 29403-29406, 1997.

45. Maehama T and Dixon JE: The tumor suppressor,PTEN/MMAC1, dephosphorylates the lipid second messenger, phosphatidylinositol 3,4,5-trisphosphate. J Biol Chem 273: 13375-13378, 1998.

46. Harima Y, Sawada S, Nagata K, Sougawa M, Ostapenko V and Ohnishi T: Mutation of the PTEN gene in advanced cervical cancer correlated with tumor progression and poor outcome after radiotherapy. Int J Oncol 18: 493-497, 2001.

47. Odar K, Boštjančič E, Gale N, Glavač D and Zidar N: Differential expression of microRNAs miR-21, miR-31, miR-203, miR-125a-5p and miR-125b and proteins PTEN and p63 in verrucous carcinoma of the head and neck. Histopathology 61: $257-265,2012$ 